\title{
Perception of Dental Undergraduates and Interns towards E-Learning in Gaining Clinical Skills: A Cross-Sectional Survey
}

Vasiqa Bano ${ }^{1}$, Ali Hassan Syed ${ }^{2}$, Hashmat Gul ${ }^{3}$, Nadia Mansoor ${ }^{1}$

\begin{abstract}
Objective: To evaluate the level of acceptance of e-learning among dental interns and undergraduates of Armed Forces Institute of Dentistry (AFID).

Study Design: Cross-sectional study.

Place and Duration of Study: The study was carried out at Armed Forces Institute of Dentistry, Rawalpindi from March 2018 to September 2018.

Materials and Methods: Cross-sectional quantitative survey was conducted in 174 participants including dental interns and undergraduates. A fourteen-item questionnaire was designed and piloted. Data was tabulated and analyzed statistically using SPSS version 24.0. Categorical variables were presented as percentages. Post-stratification Fisher's exact test and chi-square test were applied. $p<0.05$ was taken as significant.

Results: Among clinical skills learning tools, more than half (54.6\%) of the participants considered hospital attachments as most effective. E-learning was considered a supportive tool for ward test preparation. Three quarters $(75.3 \%)$ stated that e-learning has improved teaching standards and enhanced student-teacher interaction. There was significant association between level of education and messenger apps ( $p=.027)$, gender with accuracy in technique ( $p=.027)$ and with supervised discussion session regarding e-videos $(p=.038)$.

Conclusion: E-learning is beneficial for ward test preparation as it develops interest in clinical attachment and helps in learning general physical examination of patients.
\end{abstract}

Key Words: Blended learning, Clinical skill, Dental education, E-learning.

How to cite this: Bano V, Syed AH, Gul H, Mansoor N. Perception of Dental Undergraduates and Interns towards E-Learning in Gaining Clinical Skills: A Cross-Sectional Survey. Life and Science. 2021;2(1): 9-13. doi: http://doi.org/10.37185/LnS.1.1.108.

This is an Open Access article distributed under the terms of the Creative Commons Attribution License (http://creativecommons.org/licenses/by/4.0), which permits unrestricted use, distribution, and reproduction in any medium, provided the original work is properly cited.

\section{Introduction}

The role of dental health educators in maximizing a learner's capacity to gain knowledge can be enhanced through use of communication technology. ${ }^{1,2}$ E-learning also called web-based learning, online learning, computer-assisted instruction, computer-assisted learning, and

${ }^{1}$ Department of Operative Dentistry/Oral Medicine Armed Forces Institute of Dentistry (AFID), Rawalpindi ${ }^{2}$ Department of Emergency

Combined Military Hospital (CMH), Cherat, KPK

${ }^{3}$ Department of Dental Materials

Army Medical College, Rawalpindi

Correspondence:

Dr. Vasiqa Bano

Department of Operative Dentistry

Armed Forces Institute of Dentistry (AFID), Rawalpindi

E-mail:vasiqaali@gmail.com

Funding Source: NIL; Conflict of Interest: NIL

Received: Mar 26, 2020; Revised: Nov 25, 2020

Accepted: 8 Jan, 2021 internet-based learning can bring a paradigm shift in teaching approach from teacher centered learning to active learner centered learning. ${ }^{3,4} \mathrm{~A}$ combination of synchronous (face-to-face) and asynchronous learning is blended learning. ${ }^{5}$ It facilitates learners to review electronic resource at their convenience; content can be updated easily and it reduces feelings of isolation, disinterest and distraction among students. ${ }^{6}$ Blended learning equips traditional teachers with necessary technological skills to efficiently focus on critical problem-solving. ${ }^{7,8}$

Dental education has evolved through the years with incorporation of different technologies to improve the motor skills of students. ${ }^{9}$ Dental faculty has reported uncertainty about benefits of e-learning and a lack of expertise in implementation applications. ${ }^{10}$ Despite growing evidence claiming that e-learning is as effective as traditional learning 
in the health sciences, including medical, dental, public health, nursing, and other allied health professional specialties, there is very limited evidence available about what works when it works and how e-learning enhances teaching and learning. ${ }^{11}$

The purpose of this study was to evaluate the level of acceptance of e-learning of dental interns and students of Armed Forces Institute of Dentistry (AFID), in improving their clinical skills. It also gave an insight into the perception of students about benefits of e-learning,

\section{Materials and Methods}

A cross-sectional quantitative survey was conducted to assess the acceptance of interns and dental undergraduates towards e-learning in gaining clinical skills. A sample size of 174 was calculated using Raosoft sample size calculator. Approval was granted by Dental Ethical Committee of the National University of Medical Sciences (No: 905/TrgABP1K2). A self-administered, fourteen-item questionnaire was designed by the authors after extensive review of the literature. . Pilot study was carried out involving thirty participants. After making necessary amendments, data collection was done. The questionnaire (Table 1) was divided into three sections: First section was regarding demographics. The second section asked respondents about sources used in gaining clinical skills where participants' responses were rated on a 5-point Likert scale. The third section covered participant preference towards "blended learning".

Data was tabulated and analyzed statistically using SPSS version 24.0 statistical software. Categorical variables were presented as percentages. Fisher's exact test was used to find association of gender and level of education with all dichotomous variables of the study questionnaire whereas Chi-square test was used to find association of gender and level of education with the study questionnaire variables based on Likert scale. $p<0.05$ was taken as significant.

\section{Results}

Out of 174 participants, $74.1 \% \quad(n=128)$ were females, $44.8 \%(n=78)$ were interns, whereas third and fourth professional BDS students comprised $25.3 \%(n=47)$ and $29.9 \%(n=52)$ of the participants, respectively. The responses of participants regarding efficacy of different tools in learning clinical skills is

\begin{tabular}{|c|c|c|c|c|c|}
\hline \multicolumn{6}{|c|}{$\begin{array}{l}\text { The study is being conducted primarily to analyze the } \\
\text { perception of undergraduate student's attitude towards e - } \\
\text { learning. I wish to assure you that any response you make } \\
\text { will be strictly confidential and will be utilized for academic } \\
\text { purposes. Security of information will be prime objective. }\end{array}$} \\
\hline \multicolumn{6}{|l|}{ Section I: } \\
\hline \multicolumn{6}{|l|}{ Gender: } \\
\hline \multicolumn{6}{|c|}{ 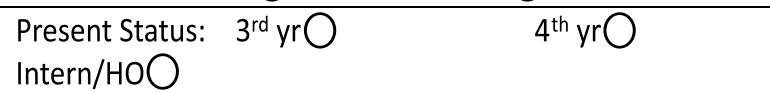 } \\
\hline \multicolumn{6}{|c|}{$\begin{array}{l}\text { Section II: Grade each statement on the given scale to } \\
\text { answer the following questions. Choose only one number } \\
\text { (1-5) for each given question. } \\
\text { (Strongly agree=5, agree=4, undecided=3, disagree=2, } \\
\text { strongly disagree=1) }\end{array}$} \\
\hline $\begin{array}{l}\text { Q. I find the following useful in my } \\
\text { learning of clinical skills: }\end{array}$ & 1 & 2 & 3 & 4 & 5 \\
\hline Hospital attachments & & & & & \\
\hline - E-learning & & & & & \\
\hline $\begin{array}{l}\text { - } \begin{array}{l}\text { Mannequins/ simulated } \\
\text { patients }\end{array} \\
\end{array}$ & & & & & \\
\hline - Textbooks & & & & & \\
\hline $\begin{array}{l}\text { - I feel that e-learning } \\
\text { encourages me to examine } \\
\text { real patients. }\end{array}$ & & & & & \\
\hline $\begin{array}{l}\text { - e-learning encourages me to } \\
\text { attend clinical attachments. }\end{array}$ & & & & & \\
\hline $\begin{array}{ll} & \text { e-learning improves } \\
& \text { standardization of teaching. }\end{array}$ & & & & & \\
\hline $\begin{array}{l}\text { - I find e-learning useful for my } \\
\text { assessment preparation (ward } \\
\text { test) in clinical skills. }\end{array}$ & & & & & \\
\hline $\begin{array}{l}\text { - } \quad \text { e-learning encourages me to } \\
\text { purchase textbooks. }\end{array}$ & & & & & \\
\hline $\begin{array}{l}\text { - I find messenger apps helpful } \\
\text { in exchanging academic links } \\
\text { and interaction with } \\
\text { teachers/students. }\end{array}$ & & & & & \\
\hline \multicolumn{6}{|l|}{ Section III: } \\
\hline \multicolumn{4}{|c|}{$\begin{array}{l}\text { Q. Do you consult on web sources if you are } \\
\text { not sure about something in clinical } \\
\text { setup/ward? }\end{array}$} & Yes & No \\
\hline \multicolumn{4}{|c|}{$\begin{array}{l}\text { Q. Do you think all the videos/tutorials } \\
\text { available on web regarding clinical skills are } \\
\text { accurate in technique? }\end{array}$} & Yes & No \\
\hline \multicolumn{4}{|c|}{$\begin{array}{l}\text { Q. Do you feel the need of supervised } \\
\text { discussion sessions to clear your concepts } \\
\text { regarding such videos/tutorials in clinical } \\
\text { environment? }\end{array}$} & Yes & No \\
\hline \multicolumn{4}{|c|}{$\begin{array}{l}\text { Q. Do you prefer a combination of traditional } \\
\text { teaching and online tutorials? }\end{array}$} & Yes & No \\
\hline
\end{tabular}

presented in Figure 2.

Among learning tools, hospital attachments were preferred the most $(54.6 \%$ strongly agreed while 


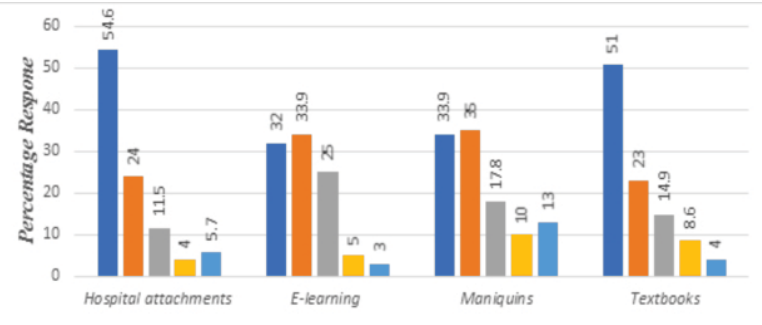

Learning Tools

Fig 1: Efficacy of Tools in Learning Clinical Skills ( $N=174)$

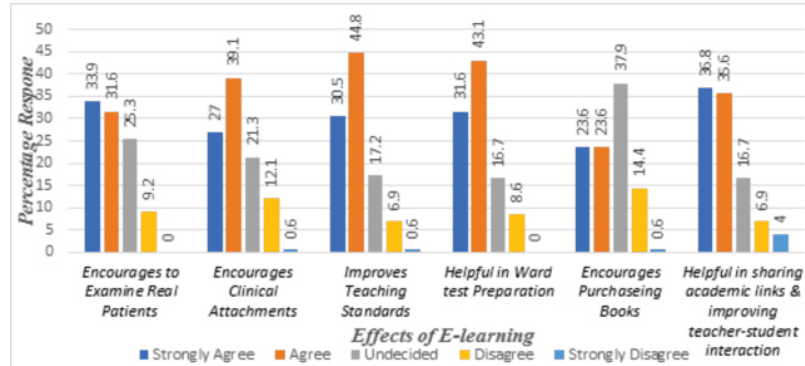

Fig 2: Opinion Regarding Effects of E-Learning ( $\mathrm{N}=174)$

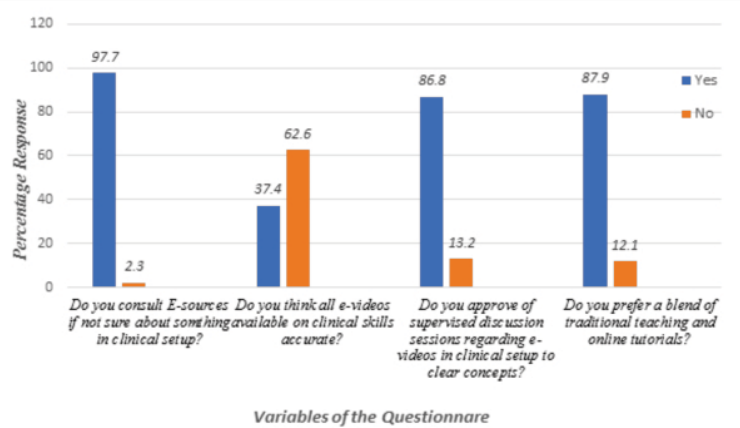

Fig 3: Evaluation of Participants Perspective Regarding ELearning ( $\mathbf{N}=\mathbf{1 7 4})$

$24 \%$ agreed). Responses of the participants regarding effects of e-learning on their learning and practicing behavior are presented in Figure 3 . Majority believed that e-learning is beneficial in improving teaching standards $(44.8 \%$ agreed and $30.5 \%$ strongly agreed) and is helpful in preparing ward tests $(43.1 \%$ agreed and $31.6 \%$ strongly agreed). However, majority were neutral (37.9\% undecided) when inquired about the impact of elearning on purchasing books. Majority of study participants (97.7\%) consulted e-sources when unsure about something in clinical set-up. Participants (86.8\%) approved of carrying out supervised discussion sessions regarding e-videos in clinical set-ups to clear concepts and $87.9 \%$ preferred a blend of traditional teaching and online tutorials for better learning and teaching of clinical skills.

Significant association of gender with accuracy in technique of e-videos $(p=.027)$ and supervised discussion session regarding e-videos $(p=038)$ (Table 2 ) was observed. The Likert scale-based e-learning variables showed no significant association with gender and level of education except between level of education and messenger apps being helpful in exchanging academic links and interaction with teachers/students $(P=.027)$ (Table 3 ).

\section{Discussion}

Majority of the study participants reported that

\begin{tabular}{|c|c|c|c|c|}
\hline \multirow{2}{*}{\multicolumn{2}{|c|}{ Variable }} & \multicolumn{2}{|c|}{ Gender } & $p$ Value \\
\hline & & Male & Female & \\
\hline \multicolumn{5}{|c|}{ Accuracy in Technique } \\
\hline \multicolumn{2}{|c|}{ No } & $22(47 \%)$ & $87(68 \%)$ & .027 \\
\hline \multicolumn{2}{|c|}{ Yes } & $23(50 \%)$ & $42(32 \%)$ & \\
\hline \multicolumn{5}{|c|}{ Supervised discussion } \\
\hline \multicolumn{2}{|c|}{ No } & $35(76 \%)$ & $116(90 \%)$ & \\
\hline \multicolumn{5}{|c|}{ Yes } \\
\hline \multicolumn{5}{|c|}{$\begin{array}{l}\text { Table 3: Association of level of education with Likert scale- } \\
\text { based e-learning variables using chi-square test }(\mathrm{N}=174)\end{array}$} \\
\hline \multirow[t]{2}{*}{ Variable } & \multicolumn{3}{|c|}{ Level of Education } & $p$ \\
\hline & $3^{\text {rd }}$ Year & $4^{\text {th }}$ Year & Interns & Value \\
\hline \multicolumn{5}{|l|}{ Messenger } \\
\hline Apps: & $3(6.3 \%)$ & $2(3.86 \%)$ & $2(2.5 \%)$ & \\
\hline Strongly & $4(8.5 \%)$ & $7(13 \%)$ & $1(1.28 \%)$ & \\
\hline disagree & $6(12.7 \%)$ & $7(13 \%)$ & $16(20 \%)$ & .02 \\
\hline Disagree & $9(19 \%)$ & $18(35 \%)$ & $35(44.8 \%)$ & \\
\hline $\begin{array}{l}\text { Undecided } \\
\text { Agree }\end{array}$ & $22(46 \%)$ & $18(35 \%)$ & $24(30 \%)$ & \\
\hline Strongly & & & & \\
\hline Agree & & & & \\
\hline
\end{tabular}

hospital attachment is a valuable learning tool in gaining clinical skills followed by text books, however, this negates the findings of systematic review by Santos et al. which suggested that elearning in oral radiology is as effective as traditional learning methods. ${ }^{4}$

Interestingly, in this study percentage of undecided majority was highest in e-learning variable but with more exposure to e-learning more students might not stay undecided. Virtual reality and augmentation reality training and lessons can be useful and applied to all departments of dentistry to make the students and postgraduate trainees learn skills by 
themselves. ${ }^{12}$ New technology like augmentation reality provides virtual information thus, opening new possibilities in various fields of dentistry enabling new applications of restorative dentistry, orthodontics and endodontics. ${ }^{13}$

In current study, participants found e-learning helpful in examining real patients with confidence and they felt encouraged towards clinical attachments to polish their clinical skills. Ariana et al. reported that confidence of operator to examine patients rather than mannequins and simulated patients was significant, concluding that e-learning supplemented clinical face-to-face teaching of oral histopathology ${ }^{2}$ which is in accordance with this study. E-learning discourages re-reading or highlighting prefabricated notes allowing the learner to engage in critical learning. ${ }^{5}$

Majority of the respondents found e-learning to be helpful in preparing for ward tests by repeatedly viewing clinical demonstration tutorials online. Elearning is not part of the curriculum; rather visiting online tutorials and videos is at the participants' own will and initiation. These results reflect respondent's motivation to keep pace with new technologies. They want to deeply learn how theoretical concepts can be linked to their hands-on experience which is in accordance with the study by Marco L Di et al. ${ }^{14} \mathrm{E}$ learning, supplemented by traditional method of face-to-face teaching is effective in facilitating the learner in gaining clinical skills. Evidence on success of e-learning on healthcare professional behavior or patient outcomes was found insufficient in a review conducted by Sinclair PM et al. at University of Newcastle, Australia. ${ }^{15}$ However, no e-learning strategies can be a substitute for experience with patients. ${ }^{16}$

In this study, results indicated that participants found messenger apps for different types of technological gadgets such as mobile devices and tablets, a helpful tool in accessing academic links and interacting with teachers and students anywhere, at any time, inside and outside of the classroom. But majority were neutral in their view regarding encouragement of elearning towards purchasing textbooks.

A significant association was observed between level of education and messenger apps being helpful in exchanging academic links and interaction with teachers/students $(p=.02)$. Highest number of interns (75.64\%) found messenger apps as a useful elearning tool followed by third year professional students (70.5\%) and least by fourth year professional students (69.2\%). It may be argued that interns being expected to do clinical procedures independently, are more inclined towards the use of various media apps to learn and polish their clinical skills.

A statistically significant association was found between gender and the variable inquiring about the accuracy of e-videos on clinical skills $(p=.027)$. Majority of the female participants (67.4\%) believed that all e-videos may not be accurate in techniques indicating their reluctance to rely blindly on e-videos. A statistically significant association was also observed between gender and the variable inquiring about the approval of supervised discussion sessions in clinical set ups regarding e-videos $(P=.038)$. Greater number of females (89.9\%) as compared to males approved of supervised discussion sessions regarding e-videos in clinical set ups to clear their concepts regarding clinical procedures. Participants of this study generally agreed that they consulted web sources if uncertain about any disease management in clinical setup/ward.

Basic knowledge can be self-taught by learner but guidance for synthesis and evaluation of online tutorials can be sought from tutors in clinical setup. Development of students' professional thinking, behavior and attitudes is usually influenced by their clinical teachers as observed by Shoaib LA et al. which is in accordance with this study where majority preferred hospital attachments over other learning tools. ${ }^{17}$ Study on blended-learning techniques by Morton CE et al. pointed out that prime focus of the educator is to concentrate on enhancing retention of learners and clearing their concepts. ${ }^{5}$

In this study, $87.9 \%$ agreed that they preferred blended learning over conventional learning techniques. ${ }^{18}$ Kintu et al. showed effectiveness of blended learning is unhindered by gender. ${ }^{19}$ Another study Hes $\mathrm{R}$ et al. demonstrated that teaching communication skills to first-year medical and second-year pharmacy students through blended learning course improved skills across multiple domains. ${ }^{20}$

The limitation of this study is that it was conducted in 
only one dental college due to which number of study participants were limited. There is a need of large scale study including multiple dental colleges with large number of study participants.

\section{Conclusion}

Perception of dental undergraduates and interns towards e-learning in gaining clinical skills is positive. E-learning augments teaching methodology and helps students prepare for ward tests. Students and interns alike are inclined towards consulting esources when unsure in clinical set-up and approved of carrying out supervised discussion sessions regarding e-videos in clinical set-ups to clear concepts. Participants preferred a blend of traditional teaching and online tutorials for better learning and teaching of clinical skills. Curriculum based on blended learning is perceived to be a better choice than the conventional teaching strategy. Further research is required for adaptation of this aspect of learning.

\section{REFERENCES}

1. Alzahrani MG. The Developments of ICT and the Need for Blended Learning in Saudi Arabia. Journal of Education and Practice. 2017; 8: 79-87.

2. Ariana A, Amin M, Pakneshan S, Dolan-Evans E, Lam AK. Integration of traditional and E-learning methods to improve learning outcomes for dental students in histopathology. Journal of dental education. 2016; 80: 1140-8.

3. Asiry MA. Dental students' perceptions of an online learning. The Saudi dental journal. 2017; 29: 167-70.

4. Santos GN, Leite AF, Figueiredo PT, Pimentel NM, Flores-Mir $C$, de Melo NS, et al. Effectiveness of e-learning in oral radiology education: a systematic review. Journal of Dental Education. 2016; 80: 1126-39.

5. Morton CE, Saleh SN, Smith SF, Hemani A, Ameen A, Bennie $T D$, et al. Blended learning: how can we optimise undergraduate student engagement?. BMC medical education. 2016; 16: 195.

6. Liu Q, Peng W, Zhang F, Hu R, Li Y, Yan W. The effectiveness of blended learning in health professions: systematic review and meta-analysis. Journal of medical Internet research. 2016; 18: e2

7. Kavadella A, Tsiklakis K, Vougiouklakis G, Lionarakis A. Evaluation of a blended learning course for teaching oral radiology to undergraduate dental students. European Journal of Dental Education. 2012; 16: e88-95.
8. Kho MH, Chew KS, Azhar MN, Hamzah ML, Chuah KM, Bustam $A$, et al. Implementing blended learning in emergency airway management training: a randomized controlled trial. BMC emergency medicine. 2018; 18: 1.

9. Huang $\mathrm{TK}$, Yang $\mathrm{CH}$, Hsieh $\mathrm{YH}$, Wang JC, Hung CC. Augmented reality (AR) and virtual reality (VR) applied in dentistry. The Kaohsiung journal of medical sciences. 2018; 34:243-8.

10. Gonzalez SM, Gadbury-Amyot CC. Using Twitter for teaching and learning in an oral and maxillofacial radiology course. Journal of dental education. 2016; 80: 149-55.

11. Regmi K, Jones L. A systematic review of the factors-enablers and barriers-affecting e-learning in health sciences education. BMC medical education. 2020; 20:1-8.

12. Huang TK, Yang $\mathrm{CH}$, Hsieh $\mathrm{YH}$, Wang JC, Hung CC. Augmented reality (AR) and virtual reality (VR) applied in dentistry. The Kaohsiung journal of medical sciences. 2018; 34: 243-8.

13. Kwon HB, Park YS, Han JS. Augmented reality in dentistry: a current perspective. Acta Odontologica Scandinavica. 2018; 76: 497-503.

14. Di Marco L, Venot A, Gillois P. Does the acceptance of hybrid learning affect learning approaches in France? J Educ Eval Health Prof. 2017; 14: 24.

15. Sinclair PM, Kable A, Levett-Jones T, Booth D. The effectiveness of Internet-based e-learning on clinician behaviour and patient outcomes: a systematic review. International Journal of Nursing studies. 2016; 57: 70-81.

16. Machado RA, Bonan PR, Perez DE, Martelli Júnior H. COVID19 pandemic and the impact on dental education: discussing current and future perspectives. Brazilian oral research. 2020: 29; 34: e083.

17. Shoaib LA, Safii SH, Naimie Z, Ahmad NA, Sukumaran P, Yunus RM. Dental students' perceptions on the contribution and impact role of a clinical teacher. European Journal of Dental Education. 2018; 22: e26-34.

18. Dalmolin AC, Mackeivicz GA, Pochapski MT, Pilatti GL, Santos FA. Learning styles preferences and e-learning experience of undergraduate dental students. Revista de Odontologia da UNESP. 2018; 47: 175-82.

19. Kho MH, Chew KS, Azhar MN, Hamzah ML, Chuah KM, Bustam A, et al. Implementing blended learning in emergency airway management training: a randomized controlled trial. BMC emergency medicine. 2018; 18: 1.

20. Hess R, Hagemeier NE, Blackwelder R, Rose D, Ansari N, Branham T. Teaching communication skills to medical and pharmacy students through a blended learning course. American Journal of Pharmaceutical Education. 2016; 80: 64. 